\title{
Endoscopist controlled administration of propofol: an effective and safe method of sedation in endoscopic procedures
}

\author{
S. Sáenz-López, S. Rodríguez Muñoz, D. Rodríguez-Alcalde, A. Franco, J. C. Marín, J. de la Cruz ${ }^{1}$ and \\ J. A. Solís Herruzo
}

Department of Gastroenterology. ${ }^{1}$ Department of Epidemiology. Hospital Unviersitario 12 de Octubre. Madrid, Spain

\begin{abstract}
Objectives: propofol is a short-acting, hypnotic agent that is increasingly being used for gastrointestinal endoscopic sedation. There are concerns about the use of propofol by non anesthesiologists due to its potential for respiratory and cardiovascular depression. This report describes our experience concerning effectiveness and safety of propofol administered in endoscopic procedures by the endoscopist and the assistant nurse.
\end{abstract}

Methods: in this prospective study, a total of 102 consecutive endoscopies (60 colonoscopies and 42 upper endoscopies) performed under sedation with propofol were included. In 27 (26.47\%) endoscopies propofol was administered alone and in 75 endoscopies (73.53\%) it was combined with benzodiazepines and/or opioids. Seventy-six (74.51\%) endoscopies were performed in patients under 65 years of age and 26 (25.49\%) in patients over 65 years of age. Ninety-one (89.22\%) endoscopies were performed in patients with low surgical risk (ASA I-II) and 11 $(10.78 \%)$ in patients with high surgical risk. The medication was administered by the endoscopist that performed the procedure and the assistant nurse.

Results: the mean dose of propofol used was $72.14 \mathrm{mg}$ for gastroscopies and 71.33 for colonoscopies $(p=0.92)$. The mean dose of propofol when infused alone was $84.81 \mathrm{mg}$ whereas in combination with benzodiazepines/opioids was $66.93 \mathrm{mg}(\mathrm{p}=$ 0.06). The doses of propofol required were lower for those colonoscopies in which midazolam and/or meperidine was combined and in patients over 65 years of age $(p=0.006$ y p $=$ 0.001 , respectively). Eleven (10.8\%) minor complications were reported, and managed by the own endoscopist. Patients had no memories of the procedure. The tolerance rated by the endoscopist was excellent-good, fair, bad-very bad in 83,5 and $12 \%$ of the gastroscopies and in 79, 8 and $13 \%$ of the colonoscopies respectively. Nevertheless bad tolerance did not hinder the completion of the procedure in any case.

Conclusions: the administration of propofol by the endoscopist and the assistant nurse, is an effective and safe method of sedation in patients of low and high-risk as well as in elderly pa-

Recibido: 04-10-05.

Aceptado: 04-10-05.

Correspondencia: Sonia Sáenz-López: Servicio de Medicina de Aparato Digestivo. Hospital Universitario 12 de Octubre. Avda. de Córdoba, s/n. 28041 Madrid. e-mail: ssaenz.hdoc@ salud.madrid.org tients. The doses of propofol required for an adequate sedation were lower in patients over 65 years of age and for colonoscopies in which medication was combined.

Key words: Propofol. Sedation. Midazolam. Meperidine.

Sáenz-López S, Rodríguez Muñoz S, Rodríguez-Alcalde D, Franco A, Marín JC, de la Cruz J, Solís Herruzo JA. Endoscopist controlled administration of propofol: an effective and safe method of sedation in endoscopic procedures. Rev Esp Enferm Dig 2006; 98: 25-35.

\section{INTRODUCTION}

Sedation and analgesia in gastrointestinal endoscopy is a common and increasing practice due to growing social pressure. Conventional sedation with benzodiazepines and opioids is being replaced by the use of propofol (1), as a single agent or in combination with standard sedatives, due to its ultrashort onset of action, its short plasma half-life and the faster recovery from sedation (2). This property makes it the ideal agent for use in ambulatory endosocopy, as it reduces post procedure surveillance (3-5). The most feared adverse effects of propofol are the respiratory depression, and the risk of hypotension and bradycardia (6). Besides, there is not an antidote for propofol. For these reasons, the administration of propofol has been primarily restricted to anesthesia and intensive care specialists. Many studies address the safe and effective administration of propofol in endoscopic procedures, controlled by the endoscopist, the trained nurse or the own patient using a target-controlled infusion of propofol, in healthy patients as well as in high-risk patients (7-34). To the best of our knowledge this is the first publication in our country, of endoscopic sedation with propofol, controlled by the endoscopist and the assistant nurse. 


\section{MATERIAL AND METHODS}

1. We developed a protocol based on the one published by Cohen et al. (35) and applied it prospectively. One hundred and two endoscopies were performed under sedation with propofol. They were carried out in $87 \mathrm{pa}-$ tients, from January 2004 to March 2005, excluding patients with known allergy to eggs, soybean or propofol as well as those suffering from obstructive sleep apnea, history of seizure disorder, short neck, inability to adequate mouth opening, and history of difficult intubation. The medication was delivered by the endoscopist performing the procedure, qualified in both basic and advanced life support skills and with the collaboration of the assistant nurse, also trained in resuscitation skills. Full resuscitation equipment was available within the endoscopy unit at all times.

Characteristics of patients concerning gender, age and ASA status were recorded (36). After completion of the procedure the following data were registered: type of endoscopic procedure, duration, indication, therapeutic procedure performed, if the exploration had been complete and if not, the reason why it had not been completed. Medication and dosage administered were also recorded. All complications that happened during the procedure were described. The adverse effects monitored were pain at the injection site or phlebitis, desaturation $\left(\mathrm{SaO}_{2}<90 \%\right)$, bradycardia $(<60 \mathrm{HR})$ and tachycardia ( $>110 \mathrm{HR}$ ), as well as the need for volume expansion, use of antidotes (anexate or naloxone) and the need for assistance or resucitation. The tolerance of the patient was rated by the endoscopist on a five point scale 1-5 $(1=$ excellent, $2=\operatorname{good}, 3=$ fair, 4 = bad, 5 = very bad). Besides, every patient was asked after the procedure if they had any memories of the procedure and if they would request the same mode of sedation in future endoscopies. The recovery time was not registered as every patient was observed for 30 minutes after completion of procedure, as determined in our protocol and irrespective of the method of sedation. The results are presented as mean and percentage and statistically analyzed with the $t$ student test or Fisher's exact test, respectively. A p value $\leq 0.05$ was regarded as statistically significant.

2. Patient monitoring. All patients were monitored continuosly by using an automated device for oxygen saturation (alarm if the oxygen saturation fell bellow 90), heart rate (alarm if the heart rate declined to less than 60 HR or exceeded $110 \mathrm{HR}$ ) and, when required, electrocardiograph, while the blood pressure was assessed at 3-minute intervals. The assistant nurse monitored chest excursion, depth of sedation and level of pain.

3. Drug administration. Intravenous access was established with an 18 to 20 gauge angiocatheter in the right forearm. During the procedure $500 \mathrm{cc}$ of saline solution were infused through an " $y$ " connector. An initial bolus of $20 \mathrm{mg}$ of propofol was infused, followed by boluses of
$10 \mathrm{mg}$ every 30 seconds until an adequate level of sedation was achieved, keeping oxygen saturation over $90 \%$. Some patients received combined medication according to the endoscopist preference. In these cases patients less than 65 years of age were given $50 \mathrm{mg}$ of meperidine and $2 \mathrm{mg}$ of midazolam whereas those over 65 years of age were given $25 \mathrm{mg}$ of meperidine and $1 \mathrm{mg}$ of midazolam. Medications were adjusted according to the patient conditions and the endoscopist criteria. All patients were given oxygen at 4 1/min by nasal cannula.

\section{RESULTS}

The characteristics of the patients are showin in table I. Fifty-eight out of 102 (56.8\%) endoscopies were performed in women. Mean age was 49,7 years with a range of [1877]. Seventy-six $(74.51 \%)$ endoscopies were performed in patients under 65 years of age and $26(25.49 \%)$ in patients older than 65 years of age. Ninety-one $(89.22 \%)$ endoscopies were performed in patients with low surgical risk (ASA I-II) and $11(10.78 \%)$ in patients with high surgical risk. Propofol was administered as a single agent in 27 endoscopies $(26.47 \%)$ and was combined with midazolam and/or meperidine in 75 (73.53\%). The mean dose of propofol (Table II) was $72.14 \mathrm{mg}$ for gastroscopies and 71.33 for colonoscopies $(p=0.92)$. The mean dose of propofol when used as a single agent (Table II -1) was $84.81 \mathrm{mg}$ whereas when combined with midazolam and/or meperidine (Tabla II-2) was $66.93(\mathrm{p}=0.06)$. Gastroscopies in which comedication was not used required less doses of propofol (61 versus $75.62 \mathrm{mg}$ ), but the difference was not statistically significant $(\mathrm{p}=0.4)$. The doses of propofol required for colonoscopies were significantly lower when combined with midazolam and/or meperidine: 60.46 versus $98.82 \mathrm{mg}(\mathrm{p}=0.006)$. Patients over 65 years of age (Table III) required lower doses of propofol: 53.07 versus 78.02 $\mathrm{mg}$, with a statistically significant difference $(\mathrm{p}=0.001)$. The mean dose of midazolam was 3,5 $\mathrm{mg}$ for gastroscopies and $4 \mathrm{mg}$ for colonoscopies. The mean dose of meperidine was $50 \mathrm{mg}$ for gastroscopies and $52 \mathrm{mg}$ for colonoscopies (Table IV).

Patients had no memories of the procedure and all patients said that they would be willing to receive the same mode of sedation if the procedure were repeated. The endoscopist (Table V) rated the patient tolerance as excellent-good, fair, bad-very bad in 83,5 and $12 \%$ of the gastroscopies and in 79,8 and $13 \%$ of the colonoscopies, respectively. Nevertheless the bad tolerance of the patient did not hinder the completion of the examination in any case. There were three cases of uncomplete colonoscopies $(5 \%)$ that were due to technical dificulties (dolicocolon) in one case and to complications in two cases (both sedation related). We recorded $11(10.8 \%)$ minor complications (Table VI), solved by the own endoscopist, and that consisted of two vasovagal reactions treated with atropine $(1,9 \%)$, a paradoxical reaction to midazolam 
Table I. Characteristics of patients

\begin{tabular}{ll}
\hline Age (years) & $49.7[18-77]$ \\
Female/male & $58(56.8 \%) / 44(43.2 \%)$ \\
ASA & \\
I & $61(59 \%)$ \\
II & $30(29 \%)$ \\
III & $3(3 \%)$ \\
IV & $8(8 \%)$ \\
\hline
\end{tabular}

Table II. Propofol dosage (mg)

\begin{tabular}{lcccc}
\hline & $\mathbf{n}$ & Mean & Minimum & Maximum \\
\hline Gastroscopy & 42 & 72.14 & 20 & 200 \\
Colonoscopy & 60 & 71.33 & 20 & 200 \\
\hline
\end{tabular}

Table II (1). Propofol dose (mg) as a single agent

\begin{tabular}{lcccc}
\hline & $\mathbf{n}$ & Mean & Minimum & Maximum \\
\hline Overall & 27 & 84.81 & 30 & 200 \\
Gastroscopy & 10 & 61 & 30 & 120 \\
Colonoscopy & 17 & 98.82 & 30 & 200 \\
\hline
\end{tabular}

Table II (2). Propofol dosage (mg) when combined with meperidine/midazolam

\begin{tabular}{lcccc}
\hline & $\mathbf{n}$ & Mean & Minimum & Maximum \\
\hline Overall & 75 & 66.93 & 20 & 200 \\
Gastroscopy & 32 & 75.62 & 20 & 200 \\
Colonoscopy & 43 & 60.46 & 20 & 160 \\
\hline
\end{tabular}

Table III. Propofol dosage (mg)

\begin{tabular}{lcccc}
\hline & $\mathbf{n}$ & Mean & Minimum & Maximum \\
\hline Under 65 years & 76 & 78.02 & 20 & 200 \\
Over 65 years & 26 & 53.07 & 20 & 130 \\
\hline
\end{tabular}

Table IV. Meperidine/midazolam dosage (mg)

\begin{tabular}{lcccc}
\hline & \multicolumn{2}{c}{ Colonoscopy } & \multicolumn{2}{c}{ Gastroscopy } \\
\hline \multirow{3}{*}{$N^{\circ}$} & Dose $(m g)$ & $N^{\circ}$ & Dose $(m g)$ \\
Midazolam & 41 & $52[50-100]$ & 28 & 50 \\
\hline
\end{tabular}

$(0,9 \%)$ and $8(7,8 \%)$ episodes of mild desaturation that were corrected by an increase in oxygen flow rate or the administration of antidotes. We registered a lower percentage of complications (Table VI-1, VI-2, VI-3) when propofol was used alone (3.7 versus $13.33 \%$ ), in patients over 65 years of age (7.69 vs. 11.84\%) and in high risk patients (9.09vs. $10.99 \%)$, albeit these differences were not statistically significant $(\mathrm{p}=0.28, \mathrm{p}=0.72, \mathrm{p}=0.85$ respectively). No patient needed endotracheal intubation. No cases of propofol-induced pain at the injection site or signs of phlebitis were recorded.

\section{DISCUSSION}

The administration of benzodiazepines and opioids as sedative agents by the endoscopist during endoscopic procedures is a common and accepted practice. These drugs are being replaced or associated with propofol (1) due to its advantages over benzodiazepines and opioids: faster onset of action, shorter plasma half-life, deeper levels of sedation and faster recovery from sedation (2-5,37-45). A recent study shows that propofol sedation simplifies the technical performance of colonoscopy compared to conventional sedation (46). There are concerns (47-49) about the administration of propofol by non anesthesiologists because of its adverse effects (respiratory depression, hypotension and bradycardia) (6), the narrow therapeutic window, and the lack of an antagonist for propofol. A recent study found that the use of propofol delivered by anesthesiologists was associated with a lower risk of adverse events (50). This data differs from a recent publication by Gangy et al. (51) that identified the administration of propofol as an independent risk factor for cardiovascular complications in gastrointestinal endoscopic procedures; in this study propofol was administered exclusively by anesthesiologists. This finding could be related to the use of larger doses of propofol by them (52) (deep sedation $v s$. moderate sedation). However, there was no difference in adverse events when propofol delivered by non-anesthesiologists was compared to convencional drugs by non-anesthesiologists (53), and there are no cases reported of endotracheal intubation or death due to the administration of propofol by this group. There are many publications addressing the effectiveness and safety of propofol administered by gastroenterologists, nurses supervised by gastroentelologists and the own patient with a target controlled infusion of propofol (731,35,40-46). These studies have included low and high risk patients (including cirrhotic patients who are undergoing variceal screening by gastroscopy) $(25,32,33)$ as well as basic and advanced endoscopic procedures $(8,10$, $12,15,22,27,34,40)$. In this study we have reported a percentage of minor complications of $10.8 \%$, in 11 patients, that were resolved by the own endoscopist by the use of antidotes such as midazolam and meperidine; and the administration of atropine in two cases. There was a percentage of $7.8 \%$ of desaturations, that was managed by 
Table V. Endoscopic procedure

\begin{tabular}{|c|c|c|c|}
\hline & $\mathbf{N}^{\circ}$ & & $\mathbf{N}^{\circ}$ \\
\hline Colonoscopy & 60 & Gastroscopy & 42 \\
\hline Biopsy & $5(8 \%)$ & Biopsy & $17(40 \%)$ \\
\hline Complete examination & $57(95 \%)$ & Banding & $6(14 \%)$ \\
\hline Tolerance & & PEG & $1(2 \%)$ \\
\hline 3. Fair & $5(8 \%)$ & 1. Excellent & $0(0 \%)$ \\
\hline 4. Bad & $5(8 \%)$ & 2. Good & $35(83 \%)$ \\
\hline 5. Very bad & $3(5 \%)$ & 3. Fair & $2(5 \%)$ \\
\hline Mean duration time [range] (min) & $37[15-65]$ & 4. Bad & $5(12 \%)$ \\
\hline
\end{tabular}

Table VI. Complications in endoscopic procedures

\begin{tabular}{|c|c|c|c|c|c|c|c|c|}
\hline & Description & $\begin{array}{l}\text { Age } \\
(y)\end{array}$ & Gender & ASA & $\begin{array}{l}\text { Propofol } \\
\text { (mg) }\end{array}$ & $\begin{array}{l}\text { Midazolam } \\
\text { (mg) }\end{array}$ & $\begin{array}{l}\text { Meperidine } \\
\text { (mg) }\end{array}$ & Treatment \\
\hline \multicolumn{9}{|l|}{ Colonoscopy } \\
\hline & Paradoxic reaction & & & & & & & \\
\hline & to midazolam & 49 & M & I & 100 & 7 & 50 & Anexate \\
\hline & Desaturation & 77 & $\mathrm{~F}$ & $\|$ & 120 & 2 & 50 & Oxygen \\
\hline & Desaturation & 59 & $\mathrm{~F}$ & I & 20 & 5 & 50 & Anexate \\
\hline & Vasovagal reaction & 33 & M & 1 & 120 & & & Atropine \\
\hline \multirow[t]{2}{*}{ Gastroscopy } & Desaturation & 39 & $\mathrm{~F}$ & I & 60 & 5 & 50 & Anexate \\
\hline & Desaturation & 58 & M & I & 80 & 2 & 50 & Anexate + Naloxone \\
\hline
\end{tabular}

oxygen administration in one case and by the administration of anexate and/or naloxone. This percentage of desaturations is comparable to data reported by other investigators. Cohen et al. (35) noted a $9 \%$ of desaturations in 819 endoscopic procedures under sedation with propofol. We did not find a higher incidence of complications in elderly patients nor in high risk patients as reported in previous studies $(25,32,33)$. Twenty-six endoscopies were performed in patients over 65 years of age, with a percentage of complications of $7.69 \%$ compared with the $11.84 \%$ of complications in the 76 endoscopies performed in patients under 65 years of age, although this difference was not statistically significant. Eleven endoscopies were performed in high-risk patients (ASA IIIVI), with a $9.09 \%$ of complications compared with the
$10.99 \%$ of complications recorded in the 91 endoscopies performed in low-risk patients (ASA I-II), with a non statistically significant difference. Supporting previous reports we registered lower doses of propofol required in elderly patients $(\mathrm{p}=0.001)$ and in those colonoscopies $(\mathrm{p}$ $=0.006)$ in which propofol was combined with meperidine and/or midazolam $(16,54,55)$. No patient required endotracheal intubation.

Assistance of an anesthesiologist for every patient undergoing an endoscopic procedure is not warranted and is cost prohibitive (52). The American Society of Anesthesiologists stated that propofol should be administered only by persons qualified to rescue patients from any level of sedation including general anestesia (56). Thus, the endoscopist must be specifically trained in the adminis- 
Table VI (1)

\begin{tabular}{lccc}
\hline & No combination Combination & Overall \\
\hline No complications & 26 & 65 & 91 \\
& $96.3 \%$ & $86.67 \%$ & $89.22 \%$ \\
Complications & 1 & 10 & 11 \\
& $3.7 \%$ & 13.33 & $10.78 \%$ \\
Overall & 27 & 75 & 102 \\
& $26.47 \%$ & $73.53 \%$ & $100 \%$ \\
\hline
\end{tabular}

Table VI (2)

\begin{tabular}{lccc}
\hline & $<\mathbf{6 5}$ years & $>\mathbf{6 5}$ years & Overall \\
\hline No complications & 67 & 24 & 91 \\
& $88.16 \%$ & $92.31 \%$ & $89.22 \%$ \\
Complications & 9 & 2 & 11 \\
& $11.84 \%$ & $7.69 \%$ & $10.78 \%$ \\
Overall & 76 & 26 & 102 \\
& $74.51 \%$ & $25.49 \%$ & $100 \%$ \\
\hline
\end{tabular}

Table VI (3)

\begin{tabular}{lccc}
\hline & ASA I-II & ASA III-IV & Overall \\
\hline No complications & 81 & 10 & 91 \\
& $89.01 \%$ & $90.91 \%$ & $89.22 \%$ \\
Complications & 10 & 1 & 11 \\
& $10.99 \%$ & $9.09 \%$ & $10.78 \%$ \\
Overall & 91 & 11 & 102 \\
& $89.22 \%$ & $10.78 \%$ & $100 \%$ \\
\hline
\end{tabular}

tration of propofol and should be qualified in life support skills (56-59). The administration of sedation by the endoscopist that performs the endoscopic procedure or the assistant nurse, in the absence of another person dedicated solely to the monitoring of the patient and administration of the sedation, is safe and effective as results from our study and previous publications $(15,35)$. Further prospective studies comparing the administration of propofol versus other methods of sedation in endoscopic procedures, controlled or not by anesthesiologists, and with a larger number of patients are needed before this practice can be recommended for general use.

\section{ACKNOWLEDGEMENTS}

We are grateful to Juan Diego Morillas and María Concepción del Amo Muñoz for their collaboration in this study.

\section{REFERENCES}

1. Heuss LT, Froehlich F, Beglinger C. Changing patterns of sedation and monitoring practice during endoscopy: results of a nationwide survey in Switzerland. Endoscopy 2005; 37: 161-166.

2. Shafer A, Doze VA, shafer SL, White PF. Pharmacokinetics and pharmacodynamics of propofol infusions during general anesthesia. Anesthesiology 1988; 69: 348-356.

3. Graber RG. Propofol in the endoscopy suite: an anesthesiologists perspective. Gastrontest Endosc 1999; 49: 80-806.

4. Rex DK, Overley C, Kinser K, et al. Safety of propofol administered by registered nurses with gastroenterologist supervision in 2000 endoscopic cases. Am J Gastroenterol 2002; 97: 1159-63.

5. Bell GD, Charlton JE. Colonoscopy-Is sedation neccessary and is there any role for intravenous propofol?. Endoscopy 2000; 32: 264-7.

6. Nelson BD, Barkun AN, Block KP, et al. Propofol use during gastrointestinal endoscopy. Gastrointest Endosc 2001; 53: 876-9.

7. Cohen LB, Hightower CD, Wood DA, et al. Moderate level sedation during endoscopy; a prospective study using low dose propofol, meperidine/fentanyl, and midazolam. Gastrointest Endosc 2004; 59: 95-803.

8. Vargo JJ, Zuccaro G, Dumot JA, et al. Gastroenterologist-administered propofol versus meperidine and midazolam for advanced upper endoscopy: A prospective, randomized trial. Gastroenterology 2002; 123: 8-16.

9. Ulmer BJ, Hansen JJ, Overley CA, et al. Propofol versus midazolam/fentanyl for outpatient colonoscopy: Administration by nurses supervised by endoscopists. Clin Gastroenterol Hepatol 2003; 1: 425 32 .

10. Dewitt J, Leblanc J, McHenry L, et al. Registered nurse-administered propofol sedation (RNAPS) versus midazolam and meperidine (MM) for endoscopic ultrasound (EUS): A prospective, randomized trial. Gastrointest Endosc 2003; 57: AB78.

11. Kulling D, Rothenbuhler R, Inauen W. Safety of nonanesthesist sedation with propofol for outpatient colonoscopy and esophagogastroduodenoscopy. Endoscopy 2003; 35: 679-82.

12. Vargo JJ, Zuccaro GJr, Dumot JA, et al. Gastroenterologist-administered propofol versus meperidine and midazolam for advanced upper endoscopy: a prospective, randomized trial. Gastroenterology 2002; 1: 8-16.

13. Sieg A, Hachmoeller-Eisenbach U, Eisenbach T. Prospective evaluation of complications in outpatient GI endoscopy: a survey among German gastroenterologists. Gastrointest Endosc 1997; 53: 620-6.

14. Bhardwaj G, Conlon S, Bowles J et al. Use of midazolam and propofol during colonoscopy: 7 years of experience. Am J Gastroenterol 2002; 2: 495-7.

15. Yusoff IF, Raymond G, Sahal AV, et al. Endoscopist administered propofol for upper-GI EUS is safe and effective: a prospective study in 500 patients. Gastrointest Endosc 2004; 60: 356-60.

16. Clarke AC, Chiragakis L, Hillman LC, et al. Sedation for endoscopy: the safe use of propofol by general practitior sedationists. Med J 2002; 176: 158-161.

17. Hansen JJ, Ulmer BJ, Rex DK. Technical performance of colonoscopy in patients sedated with nurse-administered propofol. Am J Gastroenterol 2004; 99: 52-6.

18. Heuss LT, Schnieper P, Drewe J, et al. Risk stratification and safe administration of propofol by registered nurses supervised by the gastroenterologist: A prospective observational study of more than 2000 cases. Gastrointest Endosc 2003; 57: 66471.

19. Campbell L, Imrie G, Doherty P, Porteous C, et al. Patient maintained sedation for colonoscopy using a target controlled infusion of propofol. Anaesthesia 2004; 59: 127-32.

20. Bright E, Rosevare C, Dalgleish D, et al. Patient-controlled sedation for colonoscopy; a randomized trial comparing patient-controlled administration of propofol and alfentanil with physician-administered midazolam and pethidine. Endoscopy 2003; 35: 683-7.

21. Heuss LT, Drewe J, Schnieper P, et al. Patient controlled versus nurse-administered sedation with propofol during colonoscopy; a prospective randomized trial. Am J Gastroenterol 2004; 99: 511-18.

22. Gillham MJ, Hutchinson RC, Carter R, et al. Patient maintained sedation for ERCP with a target-controlled infusion of propofol : a pilot study. Gastrointest Endosc 2001; 54: 14-7. 
23. Heiman DR, Tolliver BA, Weis FR, et al. Patient-controlled anesthesia for colonoscopy using propofol : results of a pilot study. South Med J 1998; 91: 560-4.

24. Roseveare C, Seavell C, Patel P, et al. Patient controlled sedation with propofol and alfentanil during colonoscopy: a pilot study. Endoscopy 1998; 30: 482-3

25. Weston BR, Chadalawada V, Chalasani N, et al. Nurse-administered propofol versus midazolam and meperidine for upper endoscopy in cirrhotic patients. Am J Gastroenterol 2003; 58: 725-32.

26. Bhardwaj G, Conlon S, Bowles J, et al. Use of midazolam and propofol during colonoscopy: 7 years of experience. Am J Gastroenterol 2000; 97: 495-7.

27. Kongkam P, Pornphisarn B, Rerknimitr R. Non-anesthetist administered propofol for ERCP; efficacy, safety profile and side effect: A prospective randomized trial. Gastrointest Endosc 2004; 59: AB127.

28. González-Huix F, Aldeguer X, Fort E, et al. Sedation without anesthesiologist in 5250 endoscopic procedures: Midazolam vs. midazolam + dolantine vs. propofol.Gastrointest Endosc 2004; 59: AB133.

29. Kulling D, Inauen W. Non-anesthetist sedation with propofol for outpatient colonoscopy and EGD is safe. Gastrointest Endosc 2003; 57: AB78.

30. Heuss LT, Schnieper P, Pflimlin E, et al. Nurse-administered sedation with propofol under observation of the endoscopist: A prospective observation study with more than 5000 patients. Gastrointest Endosc 2003; 57: AB105

31. Rex DK, Heuss LT, Walker JA. Nurse administered propofol sedation: Safety record among individual nurses and physicians in 3 centers. Am J Gastroenterol: in press.

32. Heuss LT, Schnieper P, Drewe J, et al. Conscious sedation with propofol in elderly patients: A prospective evaluation. Aliment Pharmacol Ther 2003; 17: 1493501.

33. Heuss LT, Schnieper P, Drewe J, et al. Safety of propofol for conscious sedation during endoscopic procedures in high-risk patients a prospective, controlled study. Am J Gastroenterol 2003; 98: 17517.

34. Wehrmann T, Kokabpick, Lembcke B, et al. Efficacy and safety of intravenous propofol sedation during routine ERCP: a prospective, controlled study. Gastrointest Endosc 1999; 49: 677-83.

35. Cohen LB, Dubovsky AN, Aisenberg J, Miller KM, Propofol for endoscopic sedation: a protocol for endoscopic and effective administration by the gastroenterologist. Gastrointest Endosc 2003; 58: 725-32.

36. Keats AS. The ASA classification of physical status: A recapiltulation. Anesthesiology 1978; 49: 233.

37. Hofmann C, Kiesslich R, Brackertz A, Jung M. Propofol for sedation in gastroscopy-a randomized comparison with midazolam. Z Gastroenterol 1999; 37: 589-95.

38. White PF, Negus JB. Sedative infusions during local and regional anesthesia: a comparison of midazolam and propofol. J Clin Anesth 1991; 3: 32-39.

39. Patterson KW, Casey PB, Murray JP, O'Boyle CA, Cunningham AJ. Propofol sedation for outpatient upper gastrointestinal endoscopy: comparison with midazolam. Br J Anaesth 1991; 67: 108-11.

40. Vargo JJ, Zuccaro GJr, Dumot JA, et al. Gastroenterologist-administered propofol for therapeutic upper endoscopy with graphic assessment of respiratory activity: a case series. Gastrointest Endosc 2000; 52: $250-5$.

41. Sipe BW, Rex DK, Latinovich D, et al. Propofol versus midazolam/meperidine for outpatient colonoscopy: Administration by nurses supervised by endoscopists. Gastrointest Endosc 2002; 55: 81525 (erratum in Gastrointest Endosc 2002; 56: 324.

42. Ulmer BJ, Hansen JJ, Overley CA, et al. Propofol versus midazolam/fentanyl for outpatient colonoscopy: administration by nurses supervised by endoscopists. Clin Gastroenterol Hepatol 2003; 1: 42532.

43. Walker JA, McIntyre RD, Schleinitz PF, et al. Nurse administered propofol sedation without anesthesia specialists in 9152 endoscopic cases in an ambulatory surgery center. Am J Gastroenterol 2003; 98 : 1744-50.

44. Rex DK, Overley C, Kinser K, et al. Safety of propofol administered by registered nurses with gastroenterologist supervision in 2000 endoscopic cases. Am J Gastroenterol 2002; 97: 115963.

45. Ng JM, Kong CF, Nyam D. Patient-controlled sedation with propofol for colonoscopy. Gastrointest Endosc 2001; 54: 122-6

46. Hansen JJ, Ulmer BJ, Rex DK. Technical performance of colonoscopy in patients sedated with nurse-administered propofol. Am J Gastroenterol 2004; 99: 52-6.

47. López Timoneda FR, Ramírez Armengol JA. Who should be responsible for sedation techniques in digestive endoscopy? Rev Esp Enferm Dig 2005; 97: 387-94.

48. Lancho Seco A, Fernandez Seara JJ, López Roses L. Who should be responsible for sedation techniques in digestive endoscopy? Our poin of view. Rev Esp Enferm Dig 2005; 97: 395-404.

49. Rodríguez Muñoz S. Me, the intruder. Rev Esp Enferm Dig 2005; 97 : 291.

50. Vargo JJ, Eisen GM, Faigel DO, et al. Anesthesiologist or non-anesthesiologist-administered propofol and cardiopulmonary complications for endoscopy: Which is safer? Gastrointest Endosc 2004; 59: AB93.

51. Gangi S, Saidi F, Patel K, et al. Cardiovascular complications after GI endoscopy: ocurrente and risks in a large hospital System. Gastrointest Endosc 2004; 60: 679-85.

52. Faigel DO, Baron TH, Goldstein JL, et al. Guidelines for the use of deep sedation and anesthesia for GI endoscopy. Gastrointest Endosc 2002; 56: 613-7.

53. Vargo JJ, Eisen GM, Faigel DO, et al. Cardiopulmonary complications with non-anesthesiologist-administered propofol vs. standard sedation: The CORI experience. Gastrointest Endosc 2005; 59: AB132.

54. Seifert H, Schmitt TH, Gultekin T, et al. Sedation with propofol plus midazolam versus propofol alone for interventional endoscopic procedures: a prospective, randomized study. Aliment Pharmacol Ther 2000; 14: 1207-14

55. Kazama T, Takeuchi K, Ikeda K, et al. Optimal propofol plasma concentration during upper gastrointestinal endoscopy in young, middleaged, and elderly patients. Anesthesiology 2000; 93: 662-9.

56. Practice guidelines for sedation and analgesia for nonanesthesiologists. Anesthesiology 2002; 96: 1004-17.

57. Vargo JJ, Waring JP, Faigel DO, et al. ASGE standards of Practice committee. Guidelines for the use of deep sedation and anesthesia for gastrointestinal endoscopy. Gastrointest Endosc 2002; 56-613-7 (Erratum, Gastrointest Endosc 2003; 57: 440).

58. ASGE standards of Practice committee. Sedation and monitoring of patients undergoing gastrointestinal endoscopic procedures. Gastrointest Endosc 1995; 42: 626-9.

59. ASGE training guideline for use of propofol in gastrointestinal endocopy. Gastrointest Endos 2004; 60: 167-72. 